\title{
EDUCAÇÃO AMBIENTAL E EDUCAÇÃO EM VALORES EM LIVROS DIDÁTICOS DE CIÊNCIAS NATURAIS
}

\section{Environmental Education and values education in science textbooks}

\author{
Dalva Maria Bianchini Bonotto ${ }^{1}$ \\ Angela Semprebone ${ }^{2}$
}

\begin{abstract}
Resumo: Os valores têm sido considerados importante conteúdo de ensino, sobretudo ao tratarmos de certas temáticas, como a ambiental. Procurando analisar o tratamento dado à dimensão valorativa da temática ambiental em três coleções de Ciências Naturais voltadas às séries finais do Ensino Fundamental verificamos a predominância da visão antropocêntrica, sendo a natureza valorizada em função de sua utilidade para o ser humano. O predomínio da valorização do conhecimento científico em detrimento de outras formas de conhecimento, da ação humana individual em detrimento da coletiva e a simples apresentação de leis ambientais foram outros aspectos problemáticos encontrados. Uma das coleções, entretanto, além de valorizar o trabalho coletivo dos alunos, também se destacou pela maior ênfase dada à dimensão estética, implicando uma visão de mundo menos utilitarista e um tratamento mais adequado do conteúdo valorativo da temática ambiental.
\end{abstract}

Palavras-chave: Educação ambiental. Educação em valores. Livro didático de Ciências Naturais. Ensino Fundamental.

\begin{abstract}
Values have been considered an important teaching subject mainly when it deals with certain themes like the environment. A qualitative analysis of three sets of Natural Sciences textbooks utilized in the last series of Brazilian Primary Schools has been realized aiming to identify how the values dimension of environmental themes has been focused. The dominance of anthropocentric views was shown, where nature was valued according to its utility for human beings. Additionally, other problematic aspects identified were: the prevalence of a scientific knowledge over alternative ways of knowing, the individual human action in contrast to the collective and the simplified demonstration of environmental laws. One of the analyzed sets, however, values the collective work of the students, as well emphasizes the esthetic dimension, implying a less utilitarian world view, pointing out a more appropriate treatment of the value content in the environmental themes.
\end{abstract}

Keywords: Environmental education. Values education. Science textbooks. Primary School.

${ }^{1}$ Licenciatura e Bacharelado em Ciências Biológicas. Doutorado em Educação. Docente, Departamento de
Educação, Instituto de Biociências, Universidade Estadual Paulista (Unesp), campus de Rio Claro, SP, Brasil.
<dalvambb@rc.unesp.br>
${ }^{2}$ Licenciatura e Bacharelado em Ciências Biológicas. Rio Claro, SP, Brasil. <angelasilva.sbone@yahoo.com.br>>

${ }^{1}$ Depto. de Educação, Instituto de Biociências, Unesp

Campus de Rio Claro - Rio Claro, SP

13.506-900

131

Ciência : Ed Educação, v. 16, n. 1, p. 131-148, 2010 
Bonotto, D. M. B.; Semprebone, A.

\section{Valores e a educação escolar}

Os valores estão presentes naturalmente em nossa vida, na medida em que não somos indiferentes ao que nos cerca. Por vivermos em grupo, o processo de valoração acarreta a construção de regras para as ações práticas, de forma que a sociedade subsista, mantenha a integridade e possa se desenvolver. A moralidade é, pois, construída por instituições como família, religião e escola, que obedecem aos mesmos valores e costumes, educando os indivíduos para interiorizarem a vontade objetiva de sua sociedade e de sua cultura (CHAUÍ, 2000).

As regras que constituem a moral variam de tempos em tempos e em determinadas circunstâncias, quando há mudanças nas relações entre as pessoas e grupos. Assim, a experiência efetiva da vida moral supõe o confronto contínuo entre os valores herdados (moral constituída) e os valores considerados ultrapassados (moral constituinte). A reflexão crítica sobre a experiência moral que tem por fim discutir as noções e princípios que fundamentam a conduta moral constitui o campo da ética (ARANHA e MARTINS, 1992).

Tratando da relação entre essas questões e a educação, Goergen (2005) aponta que, embora os educadores se digam comprometidos com a ética frente às ações educativas, analisando a estrutura e o cotidiano escolar constata-se que a ética tem um valor muito restrito na escola. Para muitos autores (MORIN, 2001; GRÜN, 1994) isso é resultado do paradigma reducionista da ciência moderna, que gerou a distinção entre fatos e valores, ciência e ética, privilegiando os fatos e a ciência e desprezando os demais aspectos.

Diversos autores têm discutido atualmente a questão do trabalho com valores pela escola (SHIMIZU, CORDEIRO e MENIN, 2006; HÖFFE, 2004; MENIN, 2002; PUIG, 1998). Muitos advogam a necessidade de a escola assumir de forma mais explícita e sistemática esse trabalho, envolvendo seus diferentes espaços e tempos e abrangendo os conteúdos das diferentes disciplinas e os temas interdisciplinares. No caso destes últimos, os Parâmetros Curriculares Nacionais - PCN (BRASIL, 1998), documentos lançados pelo governo federal a todo o país na década de 1990, apontaram a necessidade de a escola trabalhar com os denominados temas transversais, temas de grande interesse social a serem tratados na educação formal em todas as disciplinas escolares, ressaltando o seu conteúdo valorativo.

Shimizu, Cordeiro e Menin (2006) vislumbram, com a criação dos PCN, novos horizontes na formação do aluno para uma educação mais comprometida com a autonomia. Ao inserirem temas transversais, os PCN possibilitaram o retorno da educação moral, da ética, dos valores ao contexto e à história da educação brasileira como assunto prioritário. Mas, apesar de reconhecerem essas possibilidades, essas autoras atentam para o fato de que tais possibilidades esbarram na diversidade de questões práticas que existem no ambiente escolar e na sociedade, que interferem na realização de qualquer proposta educacional.

Frente a essas discussões envolvendo possibilidades e limites para o trabalho com valores pela escola, voltamo-nos para o tema transversal Meio Ambiente, procurando aprofundar a análise sobre tal trabalho dentro dessa temática específica. 


\section{Educação ambiental e o trabalho com valores}

Se o trabalho com valores tem sido considerado atualmente indispensável na educação escolar como um todo, sua necessidade se torna indiscutível ao lidarmos com certas temáticas, como a ambiental. Fica evidente a dimensão valorativa da educação ambiental na medida em que, ao se propor a construção de novas formas de relação sociedade-natureza (LOUREIRO, 2000), estas necessariamente se pautam em valores condizentes com essas mudanças.

De acordo com Grün (2001), diversos autores concordam que o atual sistema de valores sobre os quais nossa sociedade se apoia torna nossa civilização insustentável. Segundo esse autor, uma das principais causas da crise ambiental, que provoca a degradação do ambiente, tem sido a ética antropocêntrica presente em nossa sociedade. Tal sistema de valores concebe o ser humano como centro de todas as coisas e tudo que há no mundo existe em função dele. A natureza é vista como objeto a ser dominado, sendo ela considerada basicamente pelo seu valor de uso, perspectiva utilitarista, segundo a qual as coisas possuem valor se puderem ser úteis para o ser humano.

Nas últimas décadas diversas correntes têm se oposto a essa forma utilitarista de considerar a natureza, partindo do princípio de que a natureza possui um valor intrínseco, desvinculado de conotações utilitárias. Estas geraram uma diversidade de teorias do valor intrínseco da Natureza, buscando combater as éticas e lógicas utilitaristas, que concedem apenas valor instrumental para a natureza como um todo (GRÜN, 2007).

Segundo Leis e D’Amato (1995), uma radical oposição ao antropocentrismo é encontrada no biocentrismo, corrente na qual a natureza assume uma importância central, não sendo mais vista como objeto, mas como sujeito. Defende-se com isso a necessidade de mudança nos valores humanos e nos estilos de vida, considerando-se, exclusivamente e acima de tudo, a conservação do meio ambiente. Para esse autor, tanto o biocentrismo como o antropocentrismo são problemáticos, pois na verdade ambos, em seu radicalismo, acabam por colocar o homem fora da natureza. No primeiro, a natureza é vista como sujeito e o homem pertence ao planeta. Neste último, a natureza é o objeto e pertence ao homem, que é o sujeito. Muda-se a forma como são encarados o ser humano e a natureza, mas permanece a relação de domínio e separação entre eles.

Uma postura ética mais apropriada situar-se-ia no justo meio entre a ética antropocêntrica e a biocêntrica, apoiada "numa mudança de valores e atitudes básicas de inspiração ética” (LEIS e D’AMATO, 1995, p. 84). Esse modelo é o que mais se aproxima do que consideramos apropriado para uma ética voltada para o ambiente, em que

[...] no universo cada ser deve ser respeitado eticamente em seu nível de existência. Cada ser da natureza tem dignidade ética própria, intrínseca e independente das decisões humanas. Assim, a dignidade ética do homem se baseia em sua inteligência e liberdade que, tendo sido produzidas pela natureza, devem servi-la, protegê-la, desenvolvê-la e repô-la. (PEGORARO, 2002, p. 51-52) 
É com base nessa perspectiva, buscando fugir dos radicalismos e reconhecendo alguns aspectos positivos de vários posicionamentos, que nos voltamos para a identificação dos valores e valorações que a sociedade envolvida com a questão ambiental tem apontado. Estes podem ser encontrados no "Tratado de educação ambiental para sociedades sustentáveis e responsabilidade global", documento aprovado no Fórum das Organizações Não Governamentais durante a ECO-92, realizada pela Unesco no Rio de Janeiro. Tendo sido elaborado, após um amplo período de consulta popular, por representantes da sociedade civil reunidos no evento, esse documento pode ser considerado como representativo dos valores e anseios da sociedade (VIEZZER e OVALLES, 1994). Tal documento apresenta um conjunto de proposições nas quais se destacam:

- a valorização da vida de todos os seres, e, em consequência, da diversidade biológica, o que implica a necessidade de a sociedade rever sua posição perante os demais seres vivos do planeta;

- a valorização da diversidade cultural, abrindo-se para dialogar e aprender com outras culturas e com as diferentes formas de conhecimentos e saberes;

- a valorização de um modelo de sociedade sustentável, baseado na sustentabilidade equitativa e na qualidade de vida para todos;

- valorização da responsabilidade, solidariedade, cooperação e o diálogo, que possibilitem a participação de todos na construção desta sociedade, justa e equilibrada.

Concordando com Bonotto (2008), ao valorizar as diferentes formas de conhecimento, ressaltamos a importância de se considerar a dimensão estética. A estética, para Marin (2006), "se refere à capacidade humana de transcender o olhar imediatista sobre as coisas que compõem o mundo" (s/p.). Assim, a experiência estética pode possibilitar o reaprender o mundo de uma forma não imperativa (MARIN, 2006), perspectiva esta que se mostra sumamente importante quando se pensa nas possibilidades de construção de outro padrão de relação sociedade-natureza.

Reconhecendo a necessidade da educação ambiental e do trabalho com valores que a ele são inerentes, nossa atenção foi atraída para a questão de como concretizar esse trabalho. Concordando que uma das formas mais comuns e frequentes de se apresentarem valores na escola se dá pela informação que se transmite (ZABALZA, 2000), voltamo-nos para um recurso didático igualmente dos mais comuns e frequentes: o livro didático.

\section{O livro didático e os valores}

As atividades de ensino e aprendizagem requerem infraestrutura, e uma parte muito importante desse processo é o material didático. Diversos autores (FREITAS, 2001; LAJOLO, 1996) têm apontado a grande relevância do livro didático, por atingir um público expressivo do ponto de vista quantitativo e em processo de formação.

A importância do livro didático não se restringe aos seus aspectos pedagógicos e às suas possíveis influências na aprendizagem e desempenho dos alunos. Segundo Lajolo (1996), o livro didático também é importante por seu aspecto político e cultural, na medida em que reproduz e representa os valores em relação a uma dada visão da ciência, da história, da interpretação dos fatos e do próprio processo de transmissão de conhecimento. 
Fracalanza e Megid Neto (2006), ao discorrerem sobre o livro didático de ciências no Brasil, destacam o longo percurso que se deu envolvendo produção acadêmica, cursos, eventos e consultorias nas últimas décadas, e que possibilitam contribuir para a melhoria dos manuais escolares utilizados nas escolas públicas. Os autores, porém, permitem-nos perceber também quanto há ainda por fazer. Conforme investigação efetuada por Amaral (2006), na década de 1990, em livros didáticos das Ciências Naturais daquela década, estes revelaram um tratamento comprometedor da questão ambiental, apresentando: antropocentrismo e cientificismo exagerados, noções fragmentadas, incompletas e desarticuladas no tempo e no espaço sobre o ambiente, mensagens que continuariam implícitas nos livros didáticos atuais pela ausência de uma avaliação mais consistente nessa direção. Segundo esse autor, o filtro estabelecido para a avaliação das coleções didáticas de Ciência Naturais pelo Plano Nacional do Livro Didático PNLD $^{3}$ promovido pelo MEC em nosso país, "está predominantemente voltado para uma concepção de Educação, sem maiores conexões com as peculiaridades das concepções de Ciência e Ambiente" (AMARAL, 2006, p. 95).

Considerando essa questão e diante da importância do livro didático na formação dos alunos das escolas brasileiras, torna-se ainda válido e primordial investigar cuidadosamente a qualidade desse material. Desse modo, ao pensarmos no trabalho com valores voltados à educação ambiental, um problema despertou nossa atenção: o modo como os livros didáticos têm tratado esse conteúdo específico. $\mathrm{O}$ foco nos livros voltados à disciplina de Ciências Naturais pareceu-nos um caminho apropriado de análise, uma vez que neles as referências à natureza e ambiente são necessariamente fartas. Surgiram, a partir de todas essas reflexões, as questões: há referências explícitas e implícitas a respeito dos valores relativos à temática ambiental nos livros didáticos de Ciências Naturais? Sob qual perspectiva ética eles são apresentados?

\section{Objetivos e caminho metodológico da pesquisa}

A partir do exposto, os objetivos da presente pesquisa foram identificar, em coleções de livros didáticos de Ciências Naturais utilizadas em escolas do Ensino Fundamental, o conteúdo valorativo da temática ambiental apresentado, caracterizando como isso é feito. A investigação se desenvolveu dentro de uma abordagem qualitativa (LÜDKE e ANDRÉ, 1986), utilizando-se da análise documental. Segundo Godoy (1995), embora a inclusão da análise de documentos na pesquisa qualitativa possa parecer estranha, pois foge de alguns aspectos considerados básicos nesse tipo de pesquisa, essa inclusão se justifica quando se considera tal abordagem como uma proposta não rigidamente estruturada, permitindo a exploração de novos enfoques nos trabalhos.

3 O PNLD é o atual programa do governo federal que objetiva o atendimento de todos os alunos do Ensino Fundamental com a oferta de livros didáticos de diferentes disciplinas, os quais passam por avaliação antes de serem aceitos na lista das obras passíveis de serem escolhidas pelas escolas. Para mais informações, ver Hofling (2006). 
Bonotto, D. M. B.; Semprebone, A.

Por questão de delimitação da pesquisa, escolhemos as coleções destinadas às séries finais do Ensino Fundamental. A partir do levantamento dos livros utilizados em 2005 por escolas de quinta a oitava séries do Ensino Fundamental de uma cidade do interior paulista, foram identificadas, para serem analisadas, três coleções largamente utilizadas, cada uma composta de quatro volumes (um para cada uma das séries finais do Ensino Fundamental). ${ }^{4}$

Seguindo os passos gerais da análise de conteúdo (LÜDKE e ANDRÉ, 1986), os textos apresentados nos livros foram reiteradamente analisados, procurando-se interpretar seu significado de uma forma a mais ampla possível. Isso envolveu a análise de dois aspectos básicos: de um lado, o aspecto cognitivo, ou denotativo, de natureza objetiva; de outro lado, o significado emotivo ou conotativo, de natureza subjetiva. Ambos são importantes, pois, concordando com Bordenave (1992), esta diferença do cognitivo e de emotivo "é importante porque muitas vezes as pessoas reagem emocionalmente não à palavra em si ou a sua adequação gramatical, mas à maneira de usar a linguagem ou às circunstâncias em que ela é usada" (p. 71).

Os textos eram então lidos e relidos, buscando-se não somente o que o autor explicitamente apresentava, mas o que ele poderia estar desejando evocar. Para isso buscou-se captar palavras que comumente são usadas para conotarem "significados gratificantes" (BORDENAVE, 1992, p. 86), persuadindo o leitor. Conforme explicita esse autor, ao tratar da manipulação da linguagem, podem ser utilizados com essa intenção, entre outras:

- generalidades brilhantes: uso de expressões ambíguas e vagas, insinuando efeitos inverificáveis mais atraentes, bem como substantivos e adjetivos insinuando qualidades desejáveis;

- testemunho ou transferência de prestígio: associação do produto ou causa a figuras de prestígio;

- destaque das qualidades e silêncio quanto aos defeitos e limitações, fazendo-se o oposto com o produto ou causa oposta.

Em uma aproximação inicial, procurou-se identificar a organização geral de cada coleção. A partir dela, elaborou-se uma ficha para orientar a análise mais específica dos livros, a qual se apoiou também no "Guidelines for Analysing Environmental Values in Texts" (UNIVERSITY OF GREENWICH, 2004), e, por meio de leituras sucessivas dos textos de cada capítulo, buscou-se identificar objetos, seres, concepções e práticas que eram destacados pelo valor que lhes era dado, seja de forma explícita ou implícita. Posteriormente, buscou-se caracterizar a forma como esses valores eram apresentados: se a partir de um caráter utilitário (ou seja, o valor era atribuído por conta de uma utilidade para o ser humano) ou não; se havia a normatização referente a certos valores, anunciando-os associados a regras do que deve ou não deve ser feito, à legislação ou figuras de autoridade. Observou-se também se a dimensão estética estava presente, constituindo-se como um contraponto à perspectiva utilitarista.

A partir desse tratamento prévio dos dados, foi possível identificar alguns aspectos, considerados então nossas categorias de análise, que emergiram com destaque do conjunto, organizando-se, com isso, a caracterização do conteúdo valorativo da temática ambiental apresentada nos livros.

${ }^{4}$ São elas: Pedersoli et al. (2004); Bortolozo e Marluhi (2002); e Gowdak e Martins (2002). 


\section{Resultados e discussão}

Inicialmente, buscou-se analisar a organização geral de cada coleção, por meio da apresentação das obras, quando esta ocorria, e do exame de índices, estrutura geral do manual do professor e de cada capítulo. Procuramos com isso detectar aspectos valorativos evidenciados já nesse primeiro contato. Verificamos com isso que duas coleções (aqui denominadas I e II) eram muito semelhantes e até certo ponto tradicionais no que se refere à abordagem da temática ambiental, diferenciando-se de uma terceira (aqui denominada Coleção III) em vários aspectos. Esta última coleção, que a nosso ver apresenta características mais apropriadas com relação a essa temática, é a que destacaremos nessa descrição inicial, em contraposição às outras duas.

Observou-se, na Coleção III, a presença dos assuntos relativos ao meio ambiente articulados com praticamente todos os outros conteúdos, indicando tanto a valorização desse tema pelos autores como sua apresentação adequada, ao considerarmos o meio ambiente um tema amplo e relacionado, inclusive dentro das Ciências Naturais, às diferentes áreas e assuntos tratados nessas ciências. Isso já não acontece nas outras duas coleções. Embora procurem também uma maior integração entre as diferentes áreas (por exemplo, na Coleção I, os conteúdos relativos à Física e à Química são distribuídos em todos os livros), a abordagem da temática ambiental acaba se concentrando mais em alguns capítulos ou assuntos, o que pode dificultar, para o educando, o entendimento da complexidade do meio ambiente e da questão ambiental.

Diferentemente das coleções I e II, também foi observada a presença maior de alguns aspectos históricos permeando os assuntos tratados na Coleção III, influência provável de um especialista em História como coordenador do projeto do qual essa coleção faz parte (projeto esse que engloba também coleções de livros didáticos de Língua Portuguesa, Geografia e História). Consideramos essa abordagem muito importante para tratar da temática ambiental, concordando com Grün (2001), quando aponta que a supervalorização da dimensão presente do tempo traz um problema sério para a educação ambiental, como se vê na pergunta lançada pelo autor:

Como poderíamos pensar questões tão fundamentais como o desenvolvimento sustentado (que depende de uma ética para com as futuras gerações), e a preservação das culturas tradicionais indígenas (que depende de um respeito para com a tradição e o passado) em um currículo cuja base conceitual está atrelada a uma férrea lógica-presenteísta? (GRÜN, 2001, p. 108-109)

A observação atenta do índice dessas coleções permite perceber também uma diferença na Coleção III quanto à valorização de aspectos relativos à estética e à arte: surgem como título de módulos e tópicos, trechos de música, ditados populares e expressões na forma de trocadilhos, metáforas e alusões a produções artísticas ("A terra dança”; "Lixo é luxo"; "A rosa de Hiroschima" etc.), deixando explícita a valorização dessa dimensão. Quanto às coleções I e II, cada volume é organizado também em grandes unidades, subdivididas em capítulos, cujos títulos remetem diretamente aos conteúdos comumente indicados para o trabalho com a disciplina das Ciências Naturais, por exemplo: "Os seres vivos"; "Matéria e energia" 
Bonotto, D. M. B.; Semprebone, A.

(título de unidades da Coleção I) e "Os seres vivos"; "Noções básicas de Química" (título de unidades da Coleção II).

Analisando a apresentação comum aos quatro volumes, observamos, na apresentação da Coleção III (s/p), o destaque dado a "imagens, atividades e textos estimulantes", a fim de que o aprendizado seja mais agradável, mais uma vez desvelando o valor já identificado quanto aos aspectos artísticos/ estéticos. Também se explicita a preocupação em despertar ou instigar o interesse do aluno/ leitor pelas questões referentes ao meio ambiente, indicando com isso, já nessa apresentação, a valorização dessa temática.

$\mathrm{Na}$ apresentação da Coleção I (s/p) destaca-se a valorização dada ao conhecimento, como forma de contribuir para que o leitor/ aluno "se torne um cidadão pleno no cumprimento de seus deveres e no uso de seus direitos". A Coleção II não possui uma apresentação comum aos quatro volumes.

A partir dessas primeiras "pistas", voltamo-nos para a apresentação e análise do conteúdo mais específico dos capítulos ou módulos dos livros, o que será apresentado com base nas categorias construídas na pesquisa, que emergiram do conjunto dos dados.

\section{Visão antropocêntrica da natureza}

Em termos gerais, nas coleções analisadas foram verificados muitos posicionamentos problemáticos quanto aos valores e valorações relativas à temática ambiental. Predomina a visão antropocêntrica da natureza, com o ser humano separado e dono do ambiente, sendo os demais seres valorizados em função de sua utilidade para ele, como se observa nos trechos a seguir:

Já pensou no quanto as rochas são importantes para a vida das pessoas no planeta? [...]. (Coleção I, $5^{\circ}$ série, p. 51)

[A água] é um bem precioso; cabe a cada um de nós a responsabilidade de defender o que é nosso. (Coleção III, $5^{\circ}$ série, p. 71)

Assim como Amaral (2006), também Grün (2001) ressalta, da análise de vários livrostextos, tanto americanos quanto brasileiros, o antropocentrismo apresentado como um elemento "quase natural" nos livros didáticos, podendo-se considerar que o estudo de determinados assuntos só é apresentado por ter importância para os seres humanos. Para Grün (2001, p. 46):

[...] toda a estrutura conceitual do currículo e, mais especificamente o livro-texto, inocentemente continuam a sugerir que seres humanos são a referência única e exclusiva para tudo mais que existe no mundo.

Essa visão antropocêntrica, ainda segundo Grün (2001, p. 46), "reforça o pensamento de que humanos são separados da natureza; não só separados, mas donos dela". Nossos dados confirmam essa assertiva, evidenciando a distinção do ser humano frente aos demais seres vivos. 
No entanto, é importante assinalar que também foram encontradas, em vários momentos, considerações mais coerentes com relação a um tratamento mais adequado da temática ambiental, indicando caminhos possíveis para sua viabilização. Assim, com relação à visão antropocêntrica de mundo, esta é "quebrada", algumas vezes, nas coleções, quando se inclui o homem no ambiente ou quando se destaca a importância de seres vivos não para o ser humano, mas para outras espécies com as quais se relaciona. A valorização de um ser pela sua utilidade para outros seres que não o homem descentraliza o foco na espécie humana, afastando-nos da perspectiva estritamente antropocêntrica. Um exemplo dessa situação encontra-se no trecho a seguir:

Os recifes de coral têm vital importância para a manutenção do equilíbrio ecológico, por servirem de abrigo para uma enorme diversidade de espécies de animais marinhos. (Coleção II, $5^{\text {a }}$ série, p. 150)

Em outro exemplo, os anfíbios são valorizados, aparentemente, em um primeiro momento, frente aos demais seres vivos:

[...] os anfíbios, em geral, alimentam-se de insetos; isso os torna importantes para o equilíbrio ecológico. (Coleção II, p. 76)

No entanto, como se esse "argumento" não bastasse para a plena valorização dessa classe, é enfatizado posteriormente o que é indicado como sendo a sua "maior importância", que é voltada aos interesses humanos:

[...] ao alimentarem-se de insetos, os anfíbios estão auxiliando no combate a doenças e permitindo menor destruição de lavouras. (Coleção II, p. 79)

Em alguns trechos dos textos, percebe-se uma tentativa mais explícita de evitar a separação ser humano - demais espécies, como no trecho seguinte:

[...] a necessidade de tomar medidas para salvar nossas fontes de água se torna cada vez mais urgente, pois é uma questão de sobrevivência, não só da espécie humana, como também de todos os seres vivos que, como nós, são parte da natureza. (Coleção III, $5^{\text {a }}$ série, p. 43)

Nesse mesmo sentido, ao analisar o volume destinado à $5^{\text {a }}$ série da Coleção I, verificase que os autores abrem o capítulo "Conservando o Meio Ambiente" com algumas questões significativas para discutir a visão antropocêntrica:

As pessoas fazem parte do meio ambiente? É possível falar de meio ambiente como se a espécie humana estivesse situada fora dele, como se dele estivesse separada? Existe um meio ambiente urbano, ou seja, as cidades também são um tipo de meio ambiente? Nós fazemos parte da natureza, ou não? (Coleção I, $5^{\circ}$ série, p. 88) 
Bonotto, D. M. B.; Semprebone, A.

O Manual do Professor aponta que, neste capítulo, o aluno é desafiado a incluir ou não o ser humano no conceito de meio ambiente, decorrendo dessa decisão uma certa maneira de pensar e de lidar com o meio ambiente. Os autores afirmam, ainda, ser um dos propósitos dessa discussão:

[...] despertar no aluno a consciência de que somos parte do ambiente e de que as nossas ações e decisões trazem reflexos imediatos ou mediatos, que favorecem ou não a nossa sobrevivência [...]. A partir dessa provocação, o texto é construído de forma que o aluno supere a concepção de senso comum, reducionista, que considera como meio ambiente apenas os elementos da paisagem natural - incluindo seres vivos e não vivos -, ou das paisagens modificadas, mas excluindo delas o ser humano. (Coleção I, Manual do Professor, $5^{a}$ série, p. 24)

No entanto, no decorrer do capítulo, os autores insistentemente referem-se de forma separada aos "seres vivos do planeta" e aos "seres humanos". A nosso ver, esse tratamento distinto dos dois grupos pode dificultar a construção de uma visão inclusiva do ser humano no ambiente, que é o objetivo dos autores expresso no manual do professor. Isso demonstra quanto é difícil afastarmo-nos da visão antropocêntrica do mundo, desafio que a educação ambiental nos coloca.

A Coleção III é a que mais se destaca em relação a esse afastamento da visão antropocêntrica, seja pelas referências explícitas à necessidade de valorização dos seres não somente em função da espécie humana, seja também pela presença de um olhar estético para a natureza, conduzindo a uma perspectiva não utilitarista. É o que se pode observar no trecho a seguir:

Evidentemente, o título desse item [Bactérias: do bem ou do mal?] é apenas uma brincadeira, um jogo de palavras, pois não nos cabe julgar se um ser vivo é benéfico ou não partindo exclusivamente do ponto de vista humano. (Coleção III, 8 a série, p. 63)

Nessa coleção, apesar de também predominar uma visão utilitarista, são encontrados, em maior número, trechos que se afastam dessa perspectiva. Inclusive as autoras, por várias vezes, ressaltam a necessidade de sairmos da posição antropocêntrica, conforme se observa no trecho seguinte:

Conter a tentação da vaidade de nos considerarmos uma espécie superior é o grande desafio da humanidade. Deixar de acreditar que o mundo e todos os seres que nele vivem foram criados única e exclusivamente para o nosso desfrute é um primeiro passo. (Coleção III, $8^{a}$ série, p. 158)

Essa coleção se destaca também, como já dissemos, pela ênfase dada à dimensão estética, bastante presente ao longo da obra. Nela os autores utilizam, em grande quantidade, 
recursos diferenciados - poesias, letras de música, figuras, fotografias de obras de arte. Também sugerem, aos alunos, atividades de dramatização, buscando envolvê-los e sensibilizá-los. Tal sensibilização está sempre relacionada a valores relacionados ao conteúdo apresentado nos módulos. Por meio desses recursos são valorizadas, por exemplo, a cooperação, a responsabilidade, a natureza por sua beleza, dentre outros aspectos e elementos, como se pode observar no trecho a seguir:

Esse título [do módulo - Aquarelas do Brasil] talvez remeta a uma pintura. E é esse o objetivo que pretendemos atingir no estudo desse módulo: mostrar a beleza do nosso país, relacionando-a a diversidade encontrada na natureza. (Coleção III, $6^{\circ}$ série, p. 33)

\section{Conhecimentos e a temática ambiental}

A valorização do conhecimento (geralmente científico) aparece várias vezes ligada à ideia de preservação ou proteção dos seres vivos e ambientes, associando-se o conhecimento à mudança de atitude perante os problemas ambientais. Essa ideia é apresentada, sobretudo, nas coleções I e III, que possuem vários exemplos onde há afirmação direta ou indireta de que o conhecimento gera atitude de preservação. Na Coleção I afirma-se, de forma otimista, que:

Informadas, as pessoas tendem a incorporar o comportamento correto em seus valores, de maneira que ele fica para sempre e não muda quando a campanha [no caso, falava-se de coleta seletiva] acaba ou o assunto sai de moda. (Coleção I, $5^{a}$ série, p. 86)

$\mathrm{Na}$ Coleção III essa ideia não aparece de forma tão enfática, mas nela utiliza-se, algumas vezes, a expressão "Conhecer para preservar", como na proposta de atividade que se segue:

[...] organize, com o grupo da classe, uma campanha junto à sua comunidade que tenha como objetivo "conhecer para preservar". (Coleção III, $8^{\circ}$ série, p. 103)

Também, na Coleção III, o conhecimento histórico, muitas vezes, é trazido como forma de auxiliar o entendimento da questão ambiental:

[...] o passeio que vamos fazer de volta ao passado poderá ajudá-lo a entender a importância da relação entre o ser humano e a natureza, desde o aparecimento das primeiras civilizações. (Coleção III, $5^{\circ}$ série, p. 74)

Vale ressaltar, ainda, a valorização dos conhecimentos de comunidades tradicionais encontrada na Coleção III ( $5^{a}$ série). Sendo essa uma exceção frente à regra geral, depreende- 
Bonotto, D. M. B.; Semprebone, A.

se que o conhecimento cientifico ainda é trazido como o valor por excelência na apreensão, pelo ser humano, do mundo que o rodeia.

Sem cairmos em um maniqueísmo problemático que não permite à questão avançar, entendemos que a valorização do conhecimento científico possa e deva se dar nos livros didáticos de Ciências Naturais, uma vez que estes são destinados a aproximar os alunos das Ciências da Natureza, favorecendo o aprendizado relacionado a essa área de conhecimento. No entanto, isso não deve eliminar a possibilidade de apresentação - e consequente valorização - de outras formas de apreensão da vida, que podem colaborar para nos situarmos no mundo, complementando nossa visão em aspectos que o conhecimento científico não dá conta. Consideramos esse posicionamento mais apropriado para o tratamento da temática ambiental, indo ao encontro de diferentes autores que discutem as relações entre a questão ambiental e o modelo hegemônico de racionalidade herdado da ciência moderna (LEFF, 2002; GRUN, 2001; SANTOS, 1998).

Quanto à relação conhecer - agir, na coleção II, encontramos uma apresentação, a nosso ver, mais adequada no sentido de não relacionar tão diretamente conhecimento e mudança, em que é valorizado o conhecimento de seres vivos e do meio ambiente, pois, assim, o leitor/ aluno:

[...] poderá saber como protegê-los e como criar formas menos degradadoras de utilização dos recursos ambientais. (6 série, p. 10)

"Poderá" não é sinônimo de "fará". A relação direta do conhecimento com mudanças de atitude/ ação é inadequada, pois estas não dependem somente de conhecimentos. Concordamos com La Taille (1992) que saber não é necessariamente querer. Sem afirmar a total independência entre pensar e agir, esse autor, ao discutir o juízo e ação moral, chama a atenção para a dimensão da afetividade, geralmente desconsiderada, mas fundamental para nos predispor à ação.

\section{Aspectos legais relativos à temática ambiental}

Aspectos legais relativos à legislação ambiental, quando mencionados, o são geralmente através de simples apresentação, havendo normatização do que deve ser feito: as normas e seu cumprimento são, assim, o ponto valorizado dessa questão. Algumas vezes, as leis aparecem por meio de propostas de atividades de pesquisa, a serem realizadas pelos alunos:

Que tal você e seu grupo fazerem um levantamento, fundamentado em dados reais, da importância dos minerais para as pessoas? [...] torne seu trabalho mais completo, pesquisando também [...] se existem leis que regulamentam a extração mineral no Brasil. (Coleção I, 5ª série, p. 53)

Outras vezes solicita-se a investigação da efetividade da aplicação dessas leis:

Pesquise sobre alguns tratados firmados durante a realização da RIO92; pesquise se esses acordos estão sendo cumpridos ou não e elabore 
uma lista, indicando aqueles que tenham provocado uma mudança de atitude e aqueles que nunca saíram do papel. (Coleção III, $\sigma^{a}$ série, p. 42)

Em um trecho da Coleção III, quando essa questão é abordada, aponta-se para o problema de fiscalização, que dificulta o cumprimento das leis ambientais por todos. Também é apontada a questão da obrigatoriedade do cumprimento das leis:

[...] em alguns casos, a Justiça obriga destruidores da natureza a criar áreas de preservação muitas vezes maiores que as destruídas. É evidente que uma área destruída jamais será substituída por outra, mas é uma situação bem melhor do que a que tínhamos [...], de total impunidade. (Coleção III, $6^{a}$ série, p. 77)

Esses dados corroboram os encontrados por Carvalho et al. (1996), ao analisarem o conteúdo valorativo de materiais impressos relacionados à educação ambiental. Estes autores verificaram que, quando os materiais abordavam a questão da legislação, faziam apenas referências a ela, sem discuti-la, informando sua existência ou citando determinado capítulo ou artigo.

Chamou-nos a atenção o fato de praticamente nunca aparecer, nos livros didáticos analisados por nós, uma reflexão sobre o papel da legislação, que representa a oficialização de regras criadas pela sociedade para a resolução de conflitos e otimização da vida em comum. Questionamos quanto a apresentação simples e exclusiva de leis para serem cumpridas, não se distancia do processo educativo de formação crítica e autônoma dos indivíduos, objetivo da educação ambiental em particular e da educação de modo geral. Se considerarmos, de acordo com os pressupostos piagetianos de desenvolvimento do juízo moral (PIAGET, 1994), que o individuo pode e deve avançar de uma posição de simples obediência a regras para uma posição autônoma que possibilita a discussão e a criação das regras, esse fim deve ser propiciado e, de alguma forma, trazido para os espaços e materiais educativos. Mas não é o que ocorre, se as leis são mostradas de forma descontextualizada, apenas para informar que existem e que devem ser cumpridas.

\section{A ação perante os problemas ambientais}

Com relação à ação frente aos problemas ambientais, nas coleções analisadas são apontadas e valorizadas algumas atuações específicas dos alunos: a coleta seletiva de lixo; a redução de consumo; a educação, no sentido de informar a comunidade, produzindo-se cartazes, panfletos ou anúncios publicitários sobre assuntos discutidos em classe. Isso se observa no trecho a seguir:

Você pode contribuir para a educação da comunidade sobre os problemas do lixo. Produza um cartaz, ou panfleto, ou anúncio publicitário, para informar e estimular os comportamentos adequados em relação ao lixo. Dê ao material que você produziu o destino certo: exponha-o na escola, em casa ou em outro local de sua comunidade em que você 
Bonotto, D. M. B.; Semprebone, A.

considere que ele possa ajudar as pessoas a se educarem. (Coleção I, $5^{a}$ série, p. 87)

Pode-se observar também, a partir desse exemplo, a ênfase em uma ação individual do aluno, perdendo-se uma boa oportunidade de dirigir a atividade para um trabalho coletivo. Outras sugestões têm um caráter mais genérico e abstrato, ou muitas vezes não são dirigidas especificamente aos alunos. Propõe-se genericamente: a vida em harmonia com os outros seres ou em contato com a natureza, o controle biológico de pragas, a mudança de atitudes (com relação a poluir os rios), o uso de fontes alternativas de energia, a reciclagem, a ação em busca de melhor qualidade de vida, a ação para preservação do meio ambiente e do planeta para gerações futuras, a ação frente aos problemas ambientais, uma atitude não consumista, entre outras. A nosso ver, essas propostas, dirigidas ou não aos alunos, sem tradução em possibilidades concretas de ação, se perdem em discursos vazios, pois passam ao largo das reais possibilidades de atuação.

Vale ressaltar novamente a valorização dada na Coleção III a atividades para serem desenvolvidas coletivamente pelos alunos, indicadas tanto nos textos dos módulos como nos exercícios finais. Há propostas em praticamente todos os exercícios sugeridos ao final dos módulos, como a apresentação de temas polêmicos, seguida de sugestão de debate em grupo, com posterior montagem de dramatizações e/ ou elaboração de painéis para serem expostos na escola ou para a comunidade. Percebe-se que geralmente essas atividades exigem a intervenção do professor para a sua condução e conclusão adequadas. Caso o professor não atue favoravelmente, os alunos podem não desenvolver a proposta, ou desenvolvê-la parcialmente, restringindo suas possibilidades formativas. De qualquer forma, são propostas que estão didaticamente coerentes com a intenção de educar cidadãos participativos para o enfrentamento coletivo das questões ambientais, valorizando essa ação não somente por meio da apresentação e/ou reflexão sobre a mesma, mas por intermédio da prática vivida pelo aluno ao realizar o exercício proposto.

Ainda com relação aos níveis individual e coletivo de atuação, algumas vezes isso é explicitamente apontado nas coleções, como se observa no trecho a seguir:

O mais importante [...] é que o trabalho não se encerre só no levantamento dos problemas. É preciso buscar soluções concretas para eles. Algumas dependerão de cada um, outras dependerão de mudanças que só podem ser feitas com a participação de outras pessoas. O importante é levar a sério um princípio do ambientalismo: não fechar os olhos ou cruzar os braços diante de algo que consideramos errado. (Coleção I, $5^{a}$ série, p. 93-94)

Vale ressaltar a dicotomia que às vezes se estabelece diante desses dois níveis de ação. Destacando a ação coletiva, um trecho da Coleção III valoriza-a afirmando:

[...] isoladamente somos impotentes, [...] mas, se nos agruparmos, poderemos fazer campanhas pela carona solidária; pelo uso do transporte coletivo; ou pelo diga não ao sedentarismo: deixe seu carro em casa 
e caminhe! Além de apreciar a beleza da paisagem, estaremos ajudando nosso organismo a funcionar melhor. (Coleção III, $5^{\text {a }}$ série, p. 131)

$\mathrm{Na}$ mesma coleção, no livro da $8^{a}$ série, é valorizada a ação individual desvinculada do coletivo:

[...] tentamos mostrar que cada um precisa fazer sua parte. É como aquela história do beija-flor que tentava apagar um enorme incêndio na floresta, levando água no seu pequeno bico e despejando sobre as chamas, enquanto todos os outros animais fugiam. Ridicularizado pelos outros, devido à insignificância de seu ato, ele respondeu: "Pelo menos eu estou fazendo a minha parte". E você, tem feito a sua? (Coleção III, $8^{a}$ série, p. 79)

O discurso de "cada um faça a sua parte", que aparece em muito materiais voltados à educação ambiental (CARVALHO et al., 1996), ressaltando apenas a perspectiva individual de participação, dá-se muitas vezes em detrimento da ação coletiva, esta indispensável ao se pensar nos desafios da mudança social que se almeja para construção de uma sociedade sustentável. Sem querer apregoar a ação coletiva descuidando-se da ação individual, é preciso não se descuidar da primeira, pois a ação individual não dá conta de fazermos frente aos desafios instaurados, que envolvem o enfrentamento de poderes hegemônicos que buscam direcionar os rumos do planeta, e que estão associados a problemas ambientais. Há necessidade de que somemos esforços para a definição de estratégias que atuem no sentido da democratização e modificação da estrutura social vigente e voltadas para a consolidação de nova relação sociedade-natureza (LOUREIRO, 2000), o que somente será possível em uma sociedade coletivamente organizada.

\section{Considerações finais}

Em termos gerais, os aspectos apontados por Amaral (2006) na análise realizada em livros didáticos das Ciências Naturais da década de 1990 persistem. No entanto, vale dizer que os aspectos positivos identificados, mesmo quando aparecem em pequena proporção, apontam para as possibilidades reais de uma abordagem mais adequada da temática ambiental pelo livro didático. Caberia aos autores perceberem essa perspectiva e incrementarem-na em suas obras, de forma a colaborar para uma mudança de visão de mundo e de valorização dos seres no mundo, tarefa que o livro didático pode assumir com maior destaque do que tem feito.

Diante dos aspectos problemáticos encontrados, reconhecemos também o papel primordial do professor, o qual, na medida em que identifica tais limitações no livro didático, pode ajudar os alunos a refletirem sobre elas, além de poder/dever selecionar outros materiais que complementem o trabalho educativo, naquilo que o livro mostrar-se impróprio.

No entanto, é preciso levar em conta que, para lidar com essa questão, o professor deve possuir uma formação que possibilite a ele tanto identificar essas limitações como procurar formas apropriadas de supri-las. Considerando que, de modo geral, esse trabalho mais 
Bonotto, D. M. B.; Semprebone, A.

aprofundado sobre e com valores geralmente não faz parte da formação dos professores (BONOTTO, 2008), torna-se evidente a necessidade de investir-se em experiências de formação docente, assim como em investigações relativas à aprendizagem docente desse conteúdo de ensino.

Finalizando, ao refletirmos sobre todos esses aspectos e frente ao desafio proposto pela educação ambiental de mudança de visão de mundo, com base em valores mais apropriados, é preciso reconhecer uma dificuldade específica dessa tarefa, ao pensarmos no estranhamento que tais propostas podem causar, ao contrariarem os valores instituídos. Com relação à Coleção III (na qual predominou o tratamento considerado mais apropriado da temática ambiental), durante o contato inicial estabelecido com as escolas para identificação das coleções adotadas, foi-nos informado que os alunos de uma das escolas que a adotou não a aprecia. Apesar da análise da coleção ter se restringido basicamente à temática ambiental, a partir dessas informações algumas questões foram surgindo: qual seria a causa desse sentimento por parte dos alunos: eles não gostam da coleção por causa da abordagem diferenciada (interdisciplinar) dos conteúdos? Ou devido à grande quantidade de propostas de atividades em grupo, exigindo uma maior participação? Ou ainda devido ao uso frequente de poesias e outros trabalhos artísticos, utilizados para exploração da dimensão estética do conteúdo tratado? Seriam realmente, ou apenas, os alunos a estranhá-la ou os professores teriam alguma influência nessa avaliação?

A resposta a essas perguntas sugere a necessidade de outras pesquisas, que possam permitir uma melhor compreensão sobre as possibilidades e formas de se trabalhar em sala de aula com um livro didático que traga abordagens diferenciadas - e mais apropriadas - quanto aos valores que apresenta, sem provocar estranhamentos que prejudiquem esse trabalho.

\section{Referências}

AMARAL, I. A. Os fundamentos do ensino de Ciências e o livro didático. In: FRACALANZA, H.; MEGID NETO, J. (Orgs.). O livro didático de Ciências no Brasil. Campinas: Komedi, 2006. p. 83-123.

ARANHA, M. L. A.; MARTINS, M. H. P. Temas de Filosofia. São Paulo: Moderna, 1992.

BONOTTO, D. M. B. Educação Ambiental e Educação em Valores em um programa de formação docente. Revista Electrónica de Enseñanza de las Ciencias, v. 7, n. 2, p. 313-336, 2008.

BORDENAVE, J. D. D. O que é a comunicação. São Paulo: Brasiliense, 1992.

BORTOLOZO, S.; MARLUHI, S. Série Link da Ciência. São Paulo: Moderna, 2002.

BRASIL. Ministério da Educação e Cultura. Secretaria de Educação Fundamental.

Parâmetros Curriculares Nacionais: $5^{\circ}$ a $8^{\circ}$ séries do ensino fundamental, Temas Transversais. Brasília: MEC, 1998.

146

Ciência $\mathfrak{C}^{2}$ Educação, v. 16, n. 1, p. 131-148, 2010 
Educação Ambiental e educação em valores ...

CARVALHO, L. M. et al. Enfoque pedagógico: conceitos, valores e participação política. In: TRAJBER, R.; MANZOCHI, L. H. (Orgs.). Avaliando a Educação Ambiental no Brasil: materiais impressos. São Paulo: Gaia, 1996. p. 77-119.

CHAUÍ, M. Convite à Filosofia. São Paulo: Ática, 2000.

FRACALANZA, H.; MEGID NETO, J. (Orgs.) O livro didático de Ciências no Brasil. Campinas: Komedi, 2006.

FREITAS, J. F. Os conceitos de ecologia e ecossistema em livros didáticos de Ciências de $5^{\mathrm{a}}$ a $8^{\mathrm{a}}$ séries do Ensino Fundamental, utilizados por professores da Diretoria de Ensino da região de São Joaquim da Barra, em 1999. 2001. 58p. Trabalho de Conclusão de Curso (Bacharelado e Licenciatura em Ciências Biológicas) - Instituto de Biociências, Universidade Estadual Paulista, Rio Claro, 2001.

GODOY, A. S. Pesquisa qualitativa: tipos fundamentais. ERA - Revista de Administração de Empresas, São Paulo, v. 35, n. 3, p. 20-29, 1995.

GOERGEN, P. Educação e valores no mundo contemporâneo. Educação e Sociedade, Campinas, v. 26, n. 92, p. 983-1011, 2005. Disponível em: <http://www.scielo.br/ scielo.php?pid=S0101-73302005000300013\&script=sci_arttext $>$. Acesso em: 21 mar. 2008.

GOWDAK, D.; MARTINS, E. Coleção Ciências novo pensar. São Paulo: FTD, 2002.

GRÜN, M. A pesquisa em ética na Educação Ambiental. Pesquisa em Educação Ambiental, São Carlos, v. 2, n. 1, p. 185-205, 2007.

Ética e educação ambiental: a conexão necessária. Campinas: Papirus, 2001.

. Uma discussão sobre valores éticos em educação ambiental. Educação e

Realidade, Campinas, v. 19, n. 2, p. 171-195, 1994.

HÖFFE, O. Valores em instituições democráticas de ensino. Educação e Sociedade, Campinas, v. 25, n. 87, p. 463-479, 2004. Disponível em: <http://www.scielo.br/ scielo.php?script=sci_arttext\&pid=S0101-73302004000200008>. Acesso em: 20 mar. 2008.

HOFLING, E. M. A trajetória do Programa Nacional do Livro Didático do Ministério da Educação no Brasil. In: FRACALANZA, H.; MEGID NETO, J. (Orgs.). O livro didático de Ciências no Brasil. Campinas: Komedi, 2006. p. 19-31.

LAJOLO, M. Livro didático: um (quase) manual de usuário. Em Aberto, Brasília, v. 16, n. 69 , p. 3-7, 1996.

LA TAILLE, I. Desenvolvimento do juízo moral e afetividade ma teoria de Jean Piaget. In: .; OLIVEIRA, M. K.; DANTAS, H. (Orgs.). Piaget, Vigotsky, Wallon: teorias psicogenéticas em discussão. São Paulo: Summus Editorial, 1992. p. 47-73.

LEFF, H. Epistemologia ambiental. São Paulo: Cortez, 2002.

LEIS, H. R.; D’AMATO, J. L. O ambientalismo como movimento vital: análise de suas dimensões histórica, ética e vivencial. In: CAVALCANTI, C. (Org.). Desenvolvimento e natureza: estudos para uma sociedade sustentável. São Paulo: Cortez; Recife: Fundação Joaquim Nabuco, 1995. p. 77-103. 
Bonotto, D. M. B.; Semprebone, A.

LOUREIRO, C. F. B. Teoria social e questão ambiental: pressupostos para uma práxis crítica em educação ambiental. In: ___ _ LAYRARGUES, P. P.; CASTRO, R. S. C. (Orgs.). Sociedade e meio ambiente: a educação ambiental em debate. São Paulo: Cortez, 2000. p. 13-51.

LÜDKE, M.; ANDRÉ, M. E. D. A. Pesquisa em educação: abordagens qualitativas. São Paulo: EPU, 1986.

MARIN, A. A. A educação nos caminhos da sensibilidade estética: perspectivas comuns entre educação estética e ambiental. In: CONGRESSO IBERO-AMERICANO DE EDUCAÇÃO AMBIENTAL, 5., 2006, Joinville. Anais... Joinville: Ministério da Educação, Ministério de Meio Ambiente, 2006. Disponível em: <http://www.5iberoea.org.br>. Acesso em: 21 mar. 2008.

MENIN, M. S. S. Valores na escola. Educação e Pesquisa, São Paulo, v. 28, n. 1, p. 91-100, 2002. Disponível em: <http://www.scielo.br/scielo.php?script=sci_arttext\&pid= S1517-97022002000100006\&lng=pt\&nrm=iso\&tlng=pt>. Acesso em: 19 mar. 2008.

MORIN, E. Os sete saberes necessários à educação do futuro. São Paulo: Cortez, Brasília: Unesco, 2001.

PEDERSOLI, J. L. et al. Coleção Ciências naturais no dia-a-dia. Curitiba: Positivo, 2004.

PEGORARO, O. A. Ética e bioética: da subsistência à existência. Petrópolis: Vozes, 2002.

PIAGET, J. O juízo moral da criança. São Paulo: Summus Editorial, 1994.

PUIG, J. M. A construção da personalidade moral. São Paulo: Ática, 1998.

SANTOS, B. S. Um discurso sobre as Ciências. Porto: Edições Afrontamento, 1998.

SHIMIZU, A. M.; CORDEIRO, A. P.; MENIN, M. S. S. Ética, preconceito e educação: características das publicações em periódicos nacionais de educação, filosofia e psicologia entre 1970 e 2003. Revista Brasileira de Educação, Rio de Janeiro, v. 11, n. 31, p. 167-182, 2006. Disponível em: <http://www.scielo.br/scielo.php?script=sci_arttext\&pid=S141324782006000100012\&Ing=pt\&nrm=iso $>$. Acesso em: 19 maio 2006.

UNIVERSITY OF GREENWICH. Guidelines for analysing environmental values in texts. Teaching and Learning Resource (TLR). Greenwich (London): University of Greenwich, 2004.

VIEZZER, M.; OVALLES, O. (Orgs.). Manual Latino-americano de Educação ambiental. São Paulo: Gaia, 1994.

ZABALZA, M. B. O discurso didáctico sobre atitudes e valores no ensino. In: TRILLO, F. (Org.). Atitudes e valores no ensino. Lisboa: Instituto Piaget, 2000. p. 19-97.

Artigo recebido em setembro de 2009 e aceito em fevereiro de 2010. 